\title{
GEOLOGIA E GEOTURISMO NA CHAPADA DIAMANTINA
}

\author{
Autores \\ Dante Severo Giudice \\ Geógrafo/Geólogo \\ Departamento de Geografia \\ Universidade Católica do Salvador \\ Brasil \\ dasegu@gmail.com \\ Rosemeri Melo e Souza \\ Geógrafa \\ Doutora em Desenvolvimento Sustentável \\ Departamento de Geografia \\ Universidade Federal de Sergipe \\ Brasil
}

\section{RESUMO}

Os geólogos estiveram normalmente voltados aos estudos tradicionais referentes à caracterização composicional e estrutural das litologias, e a localização e estudo de jazidas. No entanto a geologia começa a atuar em outras vertentes, tais como o turismo, já conhecida como Geoturismo, que nasceu da idéia de se visitar os atrativos geológicos diretamente onde eles se encontram. A Chapada Diamantina, situada na parte central do estado da Bahia, detém grande potencial turístico, devido a sua geodiversidade, representado pelos geótopos ou geossítios, sendo necessária apenas uma sistematização de roteiros que efetivamente propiciem ao visitante conhecer e interpretar as feições existentes.

Palavras-chaves: Geologia, turismo, Chapada Diamantina.

\section{RESUMEN}

Los geólogos estuvieron normalmente orientados a los estudios tradicionales referentes a la caracterización composicional y estructural de las litologías, así como a la localización y estudio de yacimientos. Sin embargo, la geología empieza a actuar en otras vertientes, tales como el turismo, ya conocido como Geoturismo, que nació de la idea de visitar los atractivos geológicos directamente donde ellos se encuentran. La Chapada Diamantina, situada en la parte central del estado de Bahía, Brasil, tiene gran potencial turístico, gracias a su geodiversidad, representada por los geotopos o geositios, haciéndose necesario solamente una sistematización de los caminos que efectivamente lleven al visitante a conocer e interpretar las formas existentes.

Palabras claves: Geología, turismo, Chapada Diamantina 


\title{
GEOLOGY AND GEOTOURISM IN LA CHAPADA DIAMANTINA
}

\author{
Authors \\ Dante Severo Giudice \\ Geógrafo/Geólogo \\ Departamento de Geografia \\ Universidade Católica do Salvador \\ Brasil \\ dasegu@gmail.com \\ Rosemeri Melo e Souza \\ Geógrafa \\ Doutora em Desenvolvimento Sustentável \\ Departamento de Geografia \\ Universidade Federal de Sergipe \\ Brasil
}

\begin{abstract}
Normally geologists have been devoted to their traditional research related to lithology and structural studies of rocks, their location on maps and to mining deposits as well. But those days are close to change because other aspects are now about to be discovered, geo-tourism, which is in fact the idea to just visit the geological points such as interesting sites, mountains and so on, where they can be found in nature. The Chapada Diamantina is located on the center portion of the state of Bahia, Brazil, and it has a great tourism potential to lure people from everywhere, because of great geo-diversity, i.e. its geological sites or outcrops. For this purpose, it is only necessary to systematize the roads that take the visitor who has special desire to know and to understand the places shown.
\end{abstract}

Key words: Geology, tourism, Diamantina plateau. 


\section{INTRODUÇÃO}

A Chapada Diamantina localiza-se na parte central do estado da Bahia, abrange trinta e três municípios. Apresenta características singulares no que se refere a aspectos naturais. Trata-se de um santuário ecológico dos mais surpreendentes, de vida selvagem dificilmente encontrada em qualquer outra região brasileira, e por isso de grande importância para o geoturismo.

Conforme Hose (1997, p. 33), o geoturismo é "a atividade de prover subsídios que possibilitem aos turistas adquirir o conhecimento necessário para compreender a geologia e geomorfologia de um local além da apreciação de sua beleza cênica”.

Nessa região estão situadas as maiores elevações da Bahia (atingindo 1.800 metros de altitude) o que se transforma em mais um atrativo já que a escalada delas (Pico das Almas, por exemplo) é um dos roteiros mais procurados. Assim do alto da serra do Sincorá, a paisagem é deslumbrante, além guardar surpresas que levarão o visitante a descobrir rios de pedras coloridas, cascatas, cachoeiras e escorregadeiras naturais, que a ação da atividade geológica produziu, e também se transformaram em grandes atrativos turísticos da região.

\section{CONSIDERAÇÕES GERAIS SOBRE TURISMO}

O turismo é uma das vertentes mais expressivas das sociedades ditas pósindustriais. O desenvolvimento do turismo está ligado tanto às políticas públicas, seja de forma espontânea ou por intermédio de planejamento, quanto ao setor privado, ou a uma ação conjunta dos dois. A atividade turística é considerada hoje uma indústria pouco poluidora, mas, na verdade, representa na atualidade uma das mais significativas formas de reprodução de capital e de captação de recursos no comércio internacional. Dessa forma, o turismo vem crescendo e se tornando um fenômeno internacional, onde se procura aventura, o autêntico e o inusitado de cada lugar, mas paradoxalmente se quer o conforto e a segurança de casa, bem como o status que a viagem oferece ao indivíduo. Na procura de sua própria epistemologia, o turismo é

Um fenômeno que por sua natureza complexa, reconhecida por todos os seus estudiosos, é um importante tema que deve ser tratado no âmbito de um quadro interativo de disciplinas de domínio conexo, em que o enfoque geográfico é de fundamental importância, uma vez que, por tradição, lida com a dualidade sociedade x natureza. Se esta característica basilar da Geografia foi sempre considerada como um elemento complicador, tido como responsável pela sua dificuldade de firmar-se como ciência no período moderno, cremos que no momento atual, à luz de novos paradigmas e com a emergência da questão ambiental, a situação vem-se 
revertendo. Nunca o discurso geográfico foi tão valorizado, a ponto de ser apropriado por outras disciplinas. Este discurso tem sido, entretanto, superficial, permeado pela retórica, necessitando de aprofundamento para assumir a qualidade de texto (RODRIGUES, 1996, p. 22).

Na geologia turística, atualmente, vem-se desenvolvendo o aspecto ambiental, plenamente associado à Geografia Física, denominado turismo ecológico. No entanto, observa-se que

Estes referenciais teóricos da contemporaneidade correspondem ao paradigma emergente das ciências sociais, procurando-se romper com a dicotomia sujeito-objeto na pesquisa científica. Este enfoque éfundamental nos estudos do chamado turismo ecológico, em particular levando-se em consideração os paradigmas de ecologia profunda, que exigem o abandono da perspectiva antropocêntrica para um enfoque biocêntrico, em que o homem é considerado uma das espécies da natureza. Preservar a natureza, então, significa preservar o próprio homem (RODRIGUES, 1996, p. 30).

Entretanto, essa modalidade de turismo é tida como alternativa e teoricamente é capaz de conciliar a conservação do patrimônio natural (englobando o geológico) e cultural. Por outro lado, esse uso racional sob o rótulo de ecológico, pode legitimar velhas práticas do turismo tradicional predatório, já que muitas vezes o turista não está educado para tal, e as limitações existentes, não lhes são impostas, para não afugentálos.

Segundo Becker (2004), a política nacional de turismo no Brasil é inconsistente, desarticulada e ambígua quanto aos seus propósitos, contemplando hoje no país o ecoturismo como um dos principais programas de turismo.

Por outro lado

A indústria do turismo e viagens, líder mundial em movimentação de recursos e geração de empregos, que depende umbilicalmente de uma gestão sustentada dos patrimônios natural e cultural, cruza seu caminho como Brasil, o maior país tropical do mundo, proprietário e gestor do maior banco de biodiversidade do planeta. Desta relação, surge o ecoturismo como um dos mais inteligentes instrumentos de viabilização econômica, para o gerenciamento correto dos recursos naturais, oferecendo aos brasileiros uma alternativa digna de conquistar seu sustento e uma vida melhor, ao mesmo tempo em que assegura às gerações futuras, o acesso aos legados da natureza (EMBRATUR/MMA, 1994, p. 7). 
Atualmente, após a exploração turística do mundo como um todo, são os grandes geossistemas, com a sua geodiversidade, e até então preservados, do mundo tropical ou subdesenvolvido, em particular dos continentes africano e latinoamericano, os também denominados espaços de reserva de valor, que são agora chamados a entrar em cena, e serem apropriados pelo turismo internacional, pois, essa atividade

[...] nessas regiões expressa-se como verdadeiro processo civilizatório, podendo ser comparado às conquistas expansionistas das metrópoles nos territórios coloniais, na fase do capitalismo concorrencial, seja na exploração dos minérios, seja na monocultura de produtos tropicais de exportação (RODRIGUES, 1996, p. 7).

Dessa forma, os países de economia periférica, em particular do mundo tropical, com grandes e diversificados recursos turísticos naturais e culturais, têm sido objeto da intervenção por meio de megaprojetos de empresas de capitais transnacionais que dominam hegemonicamente o mercado mundial. Esses projetos têm efetivamente captado divisas, porém, a um alto custo para as populações locais e para o meio natural.

Assim sendo, mesmo nos locais mais inacessíveis, o turismo se instala com voracidade e alta tecnologia, causando total descaracterização no lugar, que passa a assumir nexos sofisticadamente urbanos, como na Chapada Diamantina, a $450 \mathrm{~km}$ de Salvador.

\section{OS ATRATIVOS TURÍSTICOS E A GEOLOGIA}

Seguramente, geologia e turismo têm muitos pontos em comum, e o turismo geológico representa uma das possibilidades para o geólogo de fazer o grande público conhecer e apreciar o território com outros olhares, pois,

[...] são muito poucos os turistas que como os geólogos têm capacidade de apreciar mais intimamente as belezas da natureza. Os geólogos interpretam também as maravilhosas estruturas internas e os efeitos dos potentes choques e majestosos escorregamentos de grandes massas de rocha que foram pouco a pouco esculpindo a crosta terrestre. O geólogo sente também a perfeita harmonia que associa as formas externas e as internas, produzida como uma sequência de causa e efeito (DESIO, 1987, p. 9).

Faz-se necessário aqui introduzir dois conceitos importantes quando se trabalha com geoturismo: um é o de patrimônio geológico, importante componente do patrimônio natural, pode ser definido como um georrecurso não renovável que pelo seu 
valor cultural, estético, econômico, funcional, científico, educativo, deva ser preservado para as gerações vindouras. O outro é o de geossítio, ou seja, sítio geológico ou sítio de interesse geológico, que pode ser qualquer território onde se consegue definir um interesse geológico-geomorfológico para conservação.

Dessa perspectiva surge o termo geoturismo que pode ser definido como turismo com base nos atrativos geológicos, que delineiam a paisagem, tais como cascatas, grutas, dentre outros, que têm uma história a contar, a história da Terra, cuja explicação vem da geologia. Entender como as paisagens tiveram origem pode vir a ser um argumento muito interessante, e a compreensão da Terra pode ser um motivo válido para se empreender uma fascinante excursão - a descoberta e o entendimento das belezas geológicas visitadas diretamente onde se encontram.

\section{O Ecoturismo na Chapada Diamantina}

No Brasil, e principalmente na Chapada Diamantina, pode-se praticar o geoturismo, tendo em vista que existe um dos mais belos e variados patrimônios geológicos do mundo.

Assim sendo, a região da Chapada Diamantina há muito tempo vem despertando atenção pelos seus atrativos naturais, decorrentes das ações físicas que produziram serras esculpidas (como a região do Pai Inácio); pela ação dos rios que deram origem a áreas alagadas (como Marimbus), belas cachoeiras (como a da Sibéria), grutas (como a Gruta Azul); dos ventos, num processo de trabalhamento que veio produzir paisagens de rara beleza cênica (Morro do Camelo); aliados a um clima ameno de altitude; tornandose, assim, de grande valor para a exploração turística.

O turismo na Chapada Diamantina é bastante explorado, na forma de lazer e recreação, sobretudo entre as cidades de Lençóis, Mucugê e Andaraí, localizadas na zona limítrofe do Parque Nacional da Chapada Diamantina, onde o ecoturismo tem se apresentado como a principal prática econômica. As formas de relevo da Chapada Diamantina (Figura 1), responsáveis pelos aspectos paisagísticos que atraem a atividade turística estão condicionadas tanto pela sua estrutura sedimentar como pela tectônica superimposta.

Figura 1: Morro do Pai Inácio - anticlinal composto de arenitos flúvio-deltáicos e 
eólicos (Fm. Tombador), sobre argilitos e siltitos (Gr. Paraguaçu).

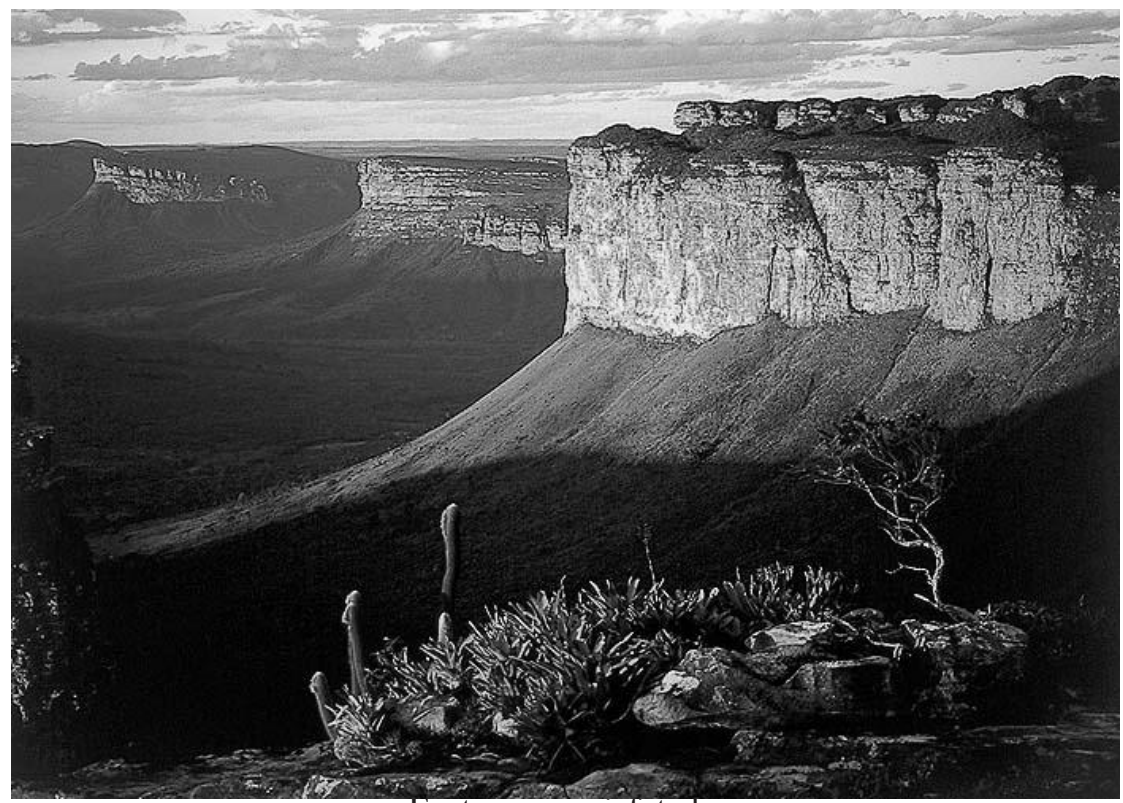

Fonte: www.Vicfoto.br

A região entre Botuporã e Rio de Contas, situada na borda oeste da Chapada Diamantina, apresenta dobramentos apertados, associados a faixas de cisalhamento, de grande extensão, os quais favoreceram a formação de serras alongadas, tais como o pico dos Barbados, de 2033 m, ponto culminante da região Nordeste, de direção NNW, exibindo vales suspensos, estreitos, intercalados (PEDREIRA, 2004). Na borda leste, entre Lençóis e Morro do Chapéu, predomina um dobramento mais aberto, com sinclinais e anticlinais de larga amplitude, que favorece a formação de platôs e morros tabulares (mesas), tais como o morro de Pai Inácio (Figura 1), em Palmeiras e o morro do Chapéu, cujas altitudes não ultrapassam a $1000 \mathrm{~m}$, intercalados a vales abertos, como o do Paty, em Lençóis. A porção nordeste, região de Iraquara, constitui um planalto cárstico que se desenvolveu nos carbonatos neoproterozóicos da Formação Salitre (MISI, 1979), onde são encontradas grutas de grande porte como a lapa Doce (mais de $12 \mathrm{~km}$ ) e Torrinha (mais de 6 km de extensão).

Dessa forma, a Chapada Diamantina se enquadra na forma do turismo paisagístico, com atrativos supracitados, onde se destaca a cachoeira do Sossego (Figura 2), situada no município de Lençóis. Esse tipo de turismo se faz na forma contemplativa, científica, de aventura ou ecoturismo, e cultural (BORDEST, 1999). 
Várias são as possibilidades de roteiros (trilhas), sendo que muitas delas já estão delimitadas e são utilizadas. No entanto, a maioria delas não visa aspectos geológicos em si, mas as estruturas deles decorrentes. Sugerimos um roteiro que parte da localidade de Capão, município de Palmeiras, até a cachoeira da Fumaça (Glass), que tem uma extensão de aproximadamente cinco quilômetros, de acesso com grau de dificuldade médio, devido à parte inicial, onde se tem de vencer a escarpa ocidental da serra do Sincorá. O restante é feito na parte plana, os Gerais, até atingir o topo da cachoeira que cai de uma altura de 420 metros, através de um abismo originado numa fenda geológica, e edificada em arenitos fluviais e eólicos, fraturados (LIMA; NOLASCO, 1997).

Assim sendo, é evidente a correlação entre a geologia e o turismo na Chapada Diamantina, uma vez que as atrações estão vinculadas as estruturas geológicas, abrigadas nas unidades de conservação, que se constituem em espaços protegidos, e que por lei preservam os recursos naturais e ecológicos da região.

\section{TURISMO COMO FATOR DE DESENVOLVIMENTO}

A nova ordem econômica mundial avança na direção do crescimento do setor terciário, que aliado a uma nova divisão social, técnica e territorial do trabalho ditam as tendências do mercado mundial. Por essa razão, as atividades do turismo se impõem e se apresentam com um novo perfil, com vertentes mais ligadas ao turismo cultural e ao ecoturismo.

No entanto, o turismo não é técnica nem ciência com independência. Ele é uma atividade que faz uso de princípios e recursos dos mais variados ramos do conhecimento, como da administração, economia, sociologia, história, e geografia que ocupa um papel de destaque, uma vez que provoca mudanças do objeto dessa ciência: o espaço.

Dentro desse contexto, toma limites a região turística, ou seja, um local caracterizado pela frequência de visitantes aliada a um volume de serviços e equipamentos turísticos. Assim, a ideia ou noção de região é repensada ou reconfigurada com outra visão, dentro de um contexto de complexidade que abrange a produção, a circulação e o consumo, com predominância da circulação sobre a produção, quer seja de bens, serviços, ou pessoas.

O turismo também implica na noção de distância que por sua vez está ligado a extensão e que remete a ideia de circulação, onde o turista-cliente funciona como instrumental de uma cadeia produtiva. Por outra perspectiva, observa-se que turismo é somente uma atividade econômica aliada a uma prática social. Ele é um fenômeno estruturante de territorialidade, que vem produzindo modos de vida dependendo da intensidade e forma como se organiza, e se recria. Esse posicionamento enfatiza 
a dimensão cultural das atividades turísticas percebendo que a cultura, enquanto um recriar é um modo de intermediação global.

O turista sempre busca um ambiente diferente daquele que está inserido diariamente sendo atraído pela imagem-imã de um lugar, que pode ter sido conhecida em uma visita virtual a um site, ou nas imagens de televisão, cinema, revistas, cartões postais, propagandas que tornam o planeta paradoxalmente disponível, mas nem sempre acessível, no sentido da experimentação, do estar presente, do vivenciar, do sentir, do acontecer. Dessa forma, o turismo contempla o lugar, aqui entendido como lugar geográfico ou lugar-identitário, ressaltando a sua vocação. O lugar "[...] é acontecer solidário da vida cotidiana, e cada lugar se define pelas existências corpórea e relacional" (SANTOS, 2002).

O turismo, portanto, se caracteriza por um campo relacional que é caracterizado pela passagem para o turista e pela permanência para o residente, e assim na categoria residente-morador existem os desdobramentos, ou seja, aqueles que nasceram no lugar e os que vieram para o lugar.

Essas características diferenciam as condições de morador, turista e nativo, refletindo modos de pertencimento, direitos políticos e os direitos de intervir na vida política do lugar. Mas, o valor do espaço depende das ações que ele é susceptível de acolher, existindo uma relação de acessibilidade e cidadania que evidencia a combinação das práticas de turismo e os efeitos que produzem nos modos de vida (SANTOS, 2002). Por outro lado, essas práticas de turismo são redefinidas pelas especificidades dos processos socioculturais da localidade, levantando uma grande preocupação em se repensar a gestão contemporânea, partindo das referências locais e do funcionamento em rede, e levando a repensar os limites local-global e a noção de lugar.

Sendo assim, o turismo deve ser planejado tentando encontrar equilíbrio entre a eficiência do crescimento econômico, igualdade na distribuição social dos recursos, e respeitando as limitações ambientais. Essa tarefa torna-se um intrincado jogo onde interesses antagônicos entram em conflito, exigindo especialistas habilidosos e projetos bem elaborados.

Na década de 1990, foi criado o Plano Nacional de Municipalização do Turismo (PNMT) que descreveu as políticas que visavam a orientação, como também, a sistematização de ações locais com o intuito da reorganização de espaços, levando em conta a questão ambiental e a gestão do território. Posteriormente, foram implantadas mudanças nesse plano, o qual passou a constituir o Programa Nacional de Regionalização do Turismo (PNRT), e transformado no Programa de Roteirização com conteúdo bem similar ao PNRT.

No contexto local, o modelo de arranjos produtivos (APLs) pode ser utilizado desde que se façam pequenas reformulações de maneira a adaptá-lo às particularidades 
da atividade. Os APLs representam redes de empresas ligadas por cadeias produtivas, fortemente interdependentes e intensamente articuladas. Essas organizações são integradas em sistemas colaborativos de produção e inovação, formando parcerias e alianças estratégicas. Como o turismo envolve amplas relações intersetoriais se faz necessário identificar, organizar e articular a sua cadeia produtiva de modo a se produzir uma análise sistêmica.

Esse enfoque integrado colabora significativamente para o desenvolvimento de políticas administrativas e para o planejamento turístico. Em uma primeira etapa, procede-se o mapeamento do arranjo produtivo do turismo que é feito a partir de uma interação que envolve atrativos naturais, infraestrutura turística, instituições de apoio local, instituições de apoio supralocal, o meio urbano e o meio rural, bem como a posição ocupada por cada um dos atores e as correlações que eles estabelecem entre si (BARBOSA; ZAMBONI, 2000). Por intermédio da extensa avaliação da cadeia produtiva do turismo é possível localizar o estágio do desenvolvimento do arranjo produtivo e identificar as potencialidades e os pontos que estão prejudicando uma integração competitiva. Esse diagnóstico fornece instrumentos para a criação de ações estratégicas que fomentem soluções para as fragilidades detetadas, desafio que cabe tanto ao setor público quanto à iniciativa privada.

Aliado à questão do desenvolvimento local está a gestão da atividade turística que como qualquer outra atividade econômica não é simples, principalmente devido as peculiaridades do produto turístico, tais como a intangibilidade, a não possibilidade de estocagem e consequentemente a não possibilidade de troca.

Na região da Chapada Diamantina, nossa área de interesse, o turismo a partir do fim da década de 70, passou a ser incrementado visando resgatar a estagnação econômica decorrente do declínio da mineração que teve seu apogeu na primeira metade do século $\mathrm{XX}$. Esse processo tornou-se mais efetivo com o aproveitamento das rugosidades deixadas pela atividade mineira e dos geossimbolos ou geossitios representados pela sua geodiversidade nos produtos turísticos naturais. Diante disso, verifica-se que os objetivos das políticas públicas de turismo são redefinidos a fim de que esse possa contribuir para o bem-estar da população residente (FONSECA, 2005).

\section{IMPLICAÇÕES AMBIENTAIS DO GEOTURISMO NA CHAPADA}

Evidentemente que associado a toda beleza cênica produzida pela ação geológica está a questão da fragilidade dos geossítios existentes na Chapada Diamantina, que a natureza levou eras para construir e que não são renováveis. Por isso, se faz necessária muita precaução na utilização desses atrativos, já que os impactos do turismo em ambientes naturais estão associados tanto à implantação de infraestrutura exigida pela atividade econômica, que muitas vezes é feita de forma ambientalmente inadequada, 
como, por exemplo, edificação de meios de hospedagem em áreas não urbanizadas; como à circulação de pessoas que a prática turística promove nos lugares.

Essas práticas, quando mal estruturadas, podem representar riscos importantes de desestabilização dos ecossistemas em que se inserem. Assim, o planejamento fisicoterritorial é o único instrumento capaz de evitar ou de minimizar possíveis impactos sobre esses ambientes. No que se refere à circulação de pessoas, os impactos mais comuns, decorrentes do turismo, sobre ambientes naturais, são aqueles associados à produção de dejetos e de lixo e, em grande parte dos casos, à incapacidade das municipalidades de lidar com a presença de uma dada população flutuante sobre seus territórios. Há também os impactos ambientais decorrentes do pisoteio das trilhas em áreas de mata, em decorrência de caminhadas feitas pelos grupos de turistas. Esses impactos, apesar de não quantificáveis, podem trazer consequências danosas.

O patrimônio natural da região da Chapada Diamantina é muito grande. A implantação de áreas de proteção e criação de parques, por si só, não leva à preservação desse patrimônio, seja pela falta de fiscalização, por razões diversas que fogem do escopo deste trabalho, seja pela falta de uma maior conscientização da população, visitante ou local, de que esse patrimônio é de todos e a todos são responsáveis pela sua preservação. Essa é uma questão educacional de base, quando se incute a noção de cidadania e de coletivo.

É evidente que falta, também, a profissionalização do turismo nessa região, afinal, nem nossos vizinhos menos desenvolvidos, oferecem visitação de graça aos seus patrimônios naturais. Não se trata de privatizar a natureza como afirmam alguns, mas regular e sistematizar o seu uso. Isso, além de trazer emprego e gerar recursos, cria uma infraestrutura básica que protege o atrativo da ação de turistas vândalos que adoram levar um souvenir de grutas e cavernas, ou registrar seus nomes nas rochas para a posteridade.

Tendo em vista que nem todos os atrativos são passíveis de serem fechados, nos locais abertos deve-se sistematizar a fiscalização e incrementar um processo de conscientização junto ao visitante.

Enfim, as agressões aos ambientes naturais podem soar como um exagero para alguns, no entanto para ambientalistas atentos, as transformações a eles impostas pelo homem, podem representar verdadeiros desastres ecológicos. 


\section{CONSIDERAÇÕES FINAIS}

O turismo e, conseqüentemente, o geoturismo têm como objetivo principal propiciar aos turistas que suas expectativas sejam alcançadas, de modo mais abrangente possível. No entanto, deve-se ter em mente que a salvaguarda das características gerais e específicas da população local é fundamental para que seja possível atingir a sustentabilidade. O geoturismo está intimamente vinculado ao meio ambiente, e dessa forma ao patrimônio ambiental (incluído o geológico), uma peça chave, uma vez que a política de preservação do meio ambiente almeja o controle do crescimento, sem que os atrativos percam a sua feição original. Assim sendo, o geoturismo sustentável procura contemplar exatamente esse equilíbrio entre desenvolvimento econômico e preservação ambiental.

No nosso caso particular, consideramos que:

- Faz-se necessário, para a consolidação do geoturismo na Chapada Diamantina, a existência de treinamento dos guias locais, com o objetivo de capacitá-los para, ao receberem os visitantes, falarem sobre a geologia local, que é o fator que rege a principal fonte de renda deles, e

- Deve ser elaborado um trabalho socioeducativo, utilizando folder simples, cartilhas, ou outros meios de comunicação visual, com o intuito de difundir a geologia e integrá-la com a comunidade em geral, divulgando os conhecimentos técnicos numa linguagem simples e de maneira clara, sem a utilização do geologuês usual. 


\section{BIBLIOGRAFIA}

- Barbosa, M. A. C.; Zamboni, R. A.(2000) Formação de um cluster em torno do turismo de natureza sustentável em Bonito-MS. Brasília: IPEA/CEPAL.

- Becker, B. K.(2004). Amazônia. Geopolítica na virada do III milênio. Rio de Janeiro: Garamond, 2004.

- Bordest, S. M. L. (1999) (Org.) Matutando turismo. Cuiabá: Ed. UFMT, 1999.

- Desio, A. (1987) Sulle vie delle sete dei ghiacci e dell"oro. Novara: Instituto Geografico de Agostini, 1987.

- EMBRATUR/MMA.(1994). As diretrizes para uma política nacional de ecoturismo da Embratur. Brasília: EMBRATUR/MMA, 1994.

- Fonseca, M. A. P. (2005). da Espaço, políticas de turismo e competitividade. Natal: Edufrn, 2005.

- Hose, T. A. (1997). Geotourism. Selling the Earth to Europe. In: MARINOS, P. G.; KOUKIS, G. C. TSIAMBAOS, G. C.; STOURNAS, G. C. (eds.) Engineering Geology and the Environment. Roterdam, Netherlands: Balkema, 1997.

- Lima. C. C. U. De; Nolasco, M. C. (s/f) Lençóis, uma ponte entre a geologia e o homem. Feira de Santana: UEFS,

- Misi, A. (1979) O Grupo Bambuí no estado da Bahia. In: INDA, H. A. V. Geologia e Recursos Minerais no Estado da Bahia, Textos Básicos. Salvador: CBPM, 1979.

- Pedreira, J. A.(2004) Serra do Sincorá, Chapada Diamantina: beleza paisagística e paleopláceres de diamante. Salvador: CPRM/Sigep, 2004.

- Rodrigues, A. A. B. (1996)(Org.) Turismo e geografia: reflexões teóricas e enfoques regionais. São Paulo: Hucitec, 1996.

- Santos, M. (2002) A natureza do espaço. São Paulo: EDUSP, 2002.

Recibido: 04/03/2010

Aprobado:01/11/2010

Arbitrado anonimamente 